effort should be directed at preventing behaviours becoming intractable or over-learned, which may mean providing much more skilled intervention from psychiatric and multi-disciplinary teams earlier in childhood.

\section{Acknowledgement}

I would like to thank the staff of the Day House for their help and co-operation.

\section{References}

FrENCH, J. (1988) Training in life skills for communitybased people with a mental handicap. British Journal of Occupational Therapy, 51, 236-238.

World Health Organization (1978) Mental Disorders: classification in accordance with ICD-9. Geneva: WHO.

ReID, A. H. \& BALlinger, B. R. (1987) Personality disorder in mental handicap. Psychological Medicine, 17, 983989.

RUBiN, L. (1987) Health care needs of adults with mental retardation. Mental Retardation, 25, 201-206.

\title{
Relative support group of long-stay psychiatric patients
}

\author{
Grace M. Leung, Topgrade Clinical Psychologist, Co-ordinator of Psychiatric \\ Rehabilitation; S. C. RASTOGI, Consultant Psychiatrist with special interest in \\ Rehabilitation; and J. Woods, Head Occupational Therapist, East Dorset Health \\ Authority, Hahnemann House, Hahnemann Road, West Hill, Bournemouth, Dorset
}

It is now widely recognised that families represent a hidden and largely unacknowledged resource to the NHS in the day to day management of long-term disabilities, particularly severe mental problems like schizophrenia. It is most likely that $50-60 \%$ of first admission schizophrenic patients will return to some type of family environment and a significant number will remain with the family for a considerable time. The current trend towards community management of mental illness, hampered by the lack of community provision, almost inevitably means discharge to families and is likely to continue and increase further.

Many families face difficult behavioural and emotional problems associated with persisting symptoms and the impairments which the illness can bring (Gibbons et al, 1984). These serve to challenge the coping resources of the family and place stress on the family unit

Despite the efforts of groups, such as the National Schizophrenia Fellowship, which have been increasingly vocal concerning the needs of families, until recently the needs of families have often been regarded with scepticism by mental health professionals. Families have been held at arm's length by mental health professionals and this has influenced the general lack of responsiveness to their needs, particularly in giving basic information about the illness, treatment and advice concerning home management (e.g. Carstairs et al, 1985). More recently, as a direct result of the renewed interest in the family environment arising from the Expressed Emotion Studies (e.g. Leff \& Vaughn, 1986), attention has been directed towards families, and earlier findings concerning their needs appear to have been rediscovered. This change in attitude is reflected in the recent report by the Select Committee on Community Services to the Mentally Ill which specifically identifies the need and importance for family support in the transfer of emphasis and resources to the community. Consequently, in recent years we have had an increasing number of initiatives which have attempted to address families' needs. These have ranged from intensive family interventions (e.g. Leff et al, 1982; Falloon et al, 1982), dedicated family services (Smith \& Birchwood, 1987) and increasing provision of relative support groups. Although family interventions have been quite systematically evaluated (Falloon and others, 1985) there has been little systematic evaluation of relative support groups in terms of meeting families' needs. The aim of the present study was therefore to identify the families caring for a relative attending Hahnemann and to assess the value of a relative support group in meeting these needs.

\section{Background to the present study}

Hahnemann House was set up in 1983 as a unit for the rehabilitation of long-stay psychiatric in-patients. There has always been a policy to involve the relatives in discussions concerning rehabilitation plans for a given individual. Many relatives commented on how 
useful these meetings had been and requested the opportunity to continue to meet with staff following discharge of the individual. In response to this, it was decided that a relative support group should be started. This study reports data from three relative support groups which have been run since they were initiated in 1984.

\section{Assessment}

The first stage of setting up the relative support group was to identify the needs of relatives of Hahnemann House. A Needs Questionnaire was developed which contained a list of potential topic areas for inclusion, based on the perceived needs of relatives from the experience of the staff and relevant research literature. Relatives were asked to rate, on a scale of $0-5$ in terms of priority, topics which they felt were most important to them for inclusion in the relatives' support group programme. Using the results of this questionnaire a programme of ten meetings was arranged.

\section{Planning}

The second stage was to run the set format for the year and at the end of each meeting each member of the group was asked to rate the usefulness of the talk on a ten point scale. At the end of the series of ten meetings each relative was asked to complete an evaluation questionnaire designed to assess the value of the support group overall. This procedure was repeated for the subsequent two groups.

\section{Sample}

Forty members of the relative groups did the assessment and questionnaire; but 35 families attended the group. The mean age of the relatives was 57 , with an age range of 30 to 75 ; most of the relatives were parents of the patients.

The patients' population in these relative groups had a long duration of schizophrenia ranging from two years to over ten years. There were 25 males and 15 females; their ages ranged from 24 to 47 years old. The majority of them were in-patients of Hahnemann House, with the rest being day patients.

\section{Format of the group}

The content of the group sessions was drawn out from the Needs Questionnaire. Each group ran from January to November each year for three years. Each meeting was designed to last from one to two hours. In the first hour there was a guest speaker on one of the chosen topics. Handouts, developed by Smith (1984) and adapted for use in the group, were provided to back up the material presented. The second hour was used for individual families to talk and discuss specific problems or for general discussion among families.

The first four meetings dealt mainly with education and knowledge specific for the members attending the groups; particularly information about schizophrenia: its symptoms, medication and its side effects; problem behaviour management, and information on resources, locally and nationally. The groups were run by three members of staff in the evening in an informal setting.

The general aims of the relatives' support group were as follows:

(a) to provide information about mental illness, its symptoms and side effects, general management of difficult behaviours and local resources available

(b) to help to develop and exchange ideas on coping skills with relatives

(c) to support and allay anxieties through specific problem solving strategies

(d) to give feedback on progress to relatives

(e) to encourage the development of a realistic but optimistic attitude towards mental illness and the role that the family can play in helping their relative stay well.

\section{Findings}

Out of the 35 members who attended the groups held over the three years, there were only 27 who returned the evaluation questionnaire (70\% response rate) about their support group. The most popular sessions were on information about the illness, medication and behaviour management. This popularity was maintained throughout three groups with full attendance. Of the 27 respondents, $90 \%$ were satisfied with the information given and what the groups set out to achieve. The remaining $10 \%$ suggested a variety of other topics to be included in the programme such as schizophrenia and food allergies; homeopathic treatment, and dealing with stress for the relatives.

Less than half the respondents attended all ten sessions; they all attended at least five sessions. A list of their positive and negative comments grouped under the headings were as follows.

(a) "We were given plenty of opportunities to talk about ourselves, problems we shared and felt that we were all in the same boat." This feeling of sharing problems and togetherness was common in their comments.

(b) "To be able to mix with staff who helped our relatives ... in order to establish confidence, trust and respect for them." This type of comment showed the appreciation of getting to know the staff better, sharing and communicating about the ill-relatives. 
(c) "... felt consoled and supported" and "these meetings are the only place where we can discuss our problems".

(d) "You need to be more disciplined as some relatives monopolised the hour by asking and talking about their own problem." This constructive feedback was obvious in many meetings where certain members monopolised the sessions.

(e) "Can cope with more detailed medical information and ongoing research on illness outcome."

(f) "Could do with more individual family time after the sessions to discuss personal issues." This illustrated the need for more staff/family interaction time.

\section{Comments}

This paper describes the setting up of three relative support groups and their subsequent evaluation after two years. From the result of the evaluation it was found that the first three sessions were rated the most valuable by the members of the groups. They thought they understood more about the illness and the sessions fulfilled their needs for attending. This finding is in line with the studies by Barrowclough et al (1987) and Smith \& Birchwood (1987) who showed that knowledge can be improved through relatively brief educational intervention. However, there were a number of difficulties, the most glaring of which was the duration of the illness. The relatives who had had to deal with the illness tried to formulate their own ideas in coping with the problems. They were more resistant to change and took longer to adapt to the new knowledge presented in the groups. Often there were heated discussions concerning strategies they have chosen to handle their crises. As Tarrier \& Barrowclough (1986) found, relatives develop an individualised view of the illness and its management which affect their acceptance or rejection of alternative information offered to them.

The second problem was that certain members were more outspoken and negative than others; they dominated sessions with their own anxieties and criticisms.

The positive aspects highlighted by the relatives were that the group provided a forum where sharing and discussion of their problems was possible; they felt "consoled and supported". In addition, the development of trust and confidence in the staff was reported and this facilitated the establishment of a link in communication between the unit and home environment. Overall the feedback was encouraging and we were asked by the relatives to continue the relative support group.

\section{Acknowledgement}

We would like to thank all the relatives and staff of Hahnemann House for their assistance in running the groups. We are indebted to Joanna Smith, Senior Clinical Psychologist, for her comments on the early version of this manuscript.

\section{References}

Barrowclough, C., Tarnier, N., Watts, S., Vaughn, C., Bamrah, J. S. \& Freeman, H. L. (1987) Assessing the functional value of relatives' knowledge about schizophrenia: A preliminary report. British Journal of Psychiatry, 151,1-8.

BIRCHWOOD, M., \& SMTT, J. E. (1986) Schizophrenia and the family. In Coping with Disorder in the Family (ed. J. Orford) London and Sidney: Croom-Helm.

Carstairs, G., Early, D., Rollin, H. \& Wing, J. (1985) Informing relatives about schizophrenia. Bulletin of the Royal College of Psychiatrists, 9, 59-60.

FALlOON, I. R. H., BOYD, J., MCGILl, C., RAzANI, J., Moss, H. \& GILDEMAN, A. (1982) Family management in the prevention and exacerbation of schizophrenia: A controlled study. New England Journal of Medicine, 306, 1437-1440.

-, and others (1985) Family Management in Schizophrenia. Baltimore and London: Johns Hopkins University Press.

Gibbons, J. S., HoRn, S. H., POWEll, J. M. \& Gibbons, J. L. (1984) Schizophrenic patients and their families. A survey in a psychiatric service based on a DGH Unit. British Journal of Psychiatry, 144, 70-77.

LefF, J., KuIPERS, L., Berkowitz, R., Eberleim-Tries, R., \& STURGEON, D. (1982) A controlled trial of social intervention in the families of schizophrenic patients. British Journal of Psychiatry, 141, 121-134.

- \& VAUGHN, C. (1986) Expressed Emotion in Families: Its Significance for Mental Illness. New York and London: Guilford Press.

Smith, J. E. \& BirchWOOd, M. (1987) Specific and nonspecific effects of educational intervention with families living with a schizophrenic relative. British Journal of Psychiatry, 150, 645-652. 